\title{
MECANISMO DE ACCIÓN DE LAS GONADOTROFINAS SOBRE EL OVARIO BOVINO Y SU PARTICIPACIÓN EN LA ENFERMEDAD QUÍSTICA OVÁRICA
}

\author{
Marelli, B. E. ${ }^{1} ;$ DíAZ, P. U. ${ }^{2}$; AMWeg, A. N. ${ }^{1,2}$; \\ ReY, F. ${ }^{1,2}$; Salvetti, N. R. ${ }^{1,2}$ \& ORTEgA, H. H. ${ }^{1,2}$
}

\begin{abstract}
RESUMEN
Las gonadotrofinas son esenciales para la función ovárica del bovino actuando, a través de la interacción con sus receptores, en la regulación del crecimiento y la maduración folicular así como en la esteroidogénesis. Se postula que cualquier modificación en los mecanismos de transcripción y/o regulación de dichos receptores podría ser un factor desencadenante de diferentes alteraciones reproductivas entre las que se encuentra la enfermedad quística ovárica (COD). La COD se define como la interrupción de los ciclos estrales normales debido a una falla en la ovulación y consecuente persistencia de un folículo que aumenta de tamaño superando el diámetro ovulatorio. Se ha demostrado que los receptores de gonadotrofinas presentan bajos niveles de expresión en ovarios enfermos en relación a ovarios sanos. Además, se han identificado una variedad de isoformas de las gonadotrofinas que podrían ejercer un rol significativo en la regulación de la expresión de los receptores funcionales e intervenir en la patogenia de la COD, siendo además, una probable causa de la falta de respuesta a los tratamientos.
\end{abstract}

Palabras claves: receptores de gonadotrofinas, ovarios, bovinos, enfermedad quística ovárica, gonadotrofinas.

\section{SUMMARY}

\section{Mechanism of action of gonadotrophins in the bovine ovary and its participation in cystic ovarian disease.}

Gonadotrophins are essential for ovarian function in cattle acting, through interaction with their receptors, in the regulation of follicular growth and maturation as in steroidogenesis. Accordingly, any change in the transcription and/or regulation mechanisms of these receptors could trigger various reproductive abnormalities such as the Cystic Ovarian Disease (COD). COD is defined as the

1.- Departamento de Ciencias Morfológicas. Facultad de Ciencias Veterinarias, Universidad Nacional del Litoral. Kreder 2805. (3080) Esperanza, provincia de Santa Fe. Email: bmarelli@fcv.unl.edu.ar 2 Consejo Nacional de Investigaciones Científicas y Técnicas (CONICET).

Manuscrito recibido el 23 de octubre de 2012 y aceptado para su publicación el 8 de abril de 2013. 
interruption of normal estrous cycles due to the persistence of a follicle increase in size, beyond the ovulatory diameter. It has been demonstrated lower expression levels of gonadotrophin receptors in diseased ovary relative to healthy ovaries. Furthermore, a variety of gonadotrophin isoforms have been identified which could play a significant role in the expression regulation of functional receptors intervening in the COD pathogenesis and being a likely cause for the lack of treatment response.

Key words: gonadotropin receptors, ovaries, cattle, cystic ovarian disease, gonadotrophin.

\section{INTRODUCCIÓN}

Las hormonas gonadotróficas luteinizante (LH) y folículoestimulante (FSH) son partes integrales del intercambio neuroendocrino del eje hipotálamo-hipofisario-gonadal que controla el ciclo estral de los rumiantes. Dichas hormonas son sintetizadas y secretadas por las células gonadotrofas adenohipofisarias luego de ser estimuladas por la interacción de la hormona liberadora de gonadotrofinas (GnRH), secretada desde el hipotálamo, con sus receptores. Luego de viajar por la circulación sanguínea, la LH y FSH se unen a sus receptores específicos en el ovario desencadenando la transducción de señales intracelulares que culminan la comunicación a la largo de dicho eje (Adams et al., 2008).

La secreción pulsátil de gonadotrofinas varía durante el ciclo estral, los pulsos de LH son de mayor frecuencia en la fase folicular, para posteriormente disminuir en la fase lútea. Respecto a la $\mathrm{FSH}$, la secreción ocurre en ondas durante la fase lútea del ciclo, alcanzando una meseta en la fase folicular, previo al pico de LH preovulatorio. Estas variaciones ocurren debido al efecto estimulador (retroalimentación positiva) e inhibidor (retroalimentación negativa) que ejercen las hormonas esteroideas ováricas, estrógenos y progesterona, sobre el eje hipotálamo-hipofisario, originando como consecuencia los ciclos reproductivos. La acción de las hormonas esteroides sobre el hipotálamo determina dos tipos de secreción de gonadotrofinas: "tónica", manteniendo niveles basales, y "cíclica”, produciendo un aumento significativo en los niveles de LH y FSH, según la fase del ciclo, como se describió anteriormente (Adams et al., 2008).

Al comienzo de la fase folicular, los folículos inmaduros secretan bajas cantidades de estrógenos que inducen un efecto de retroalimentación negativa en el hipotálamo e hipófisis, provocando la secreción tónica de FSH y LH. Cuando uno de los folículos alcanza la fase preovulatoria, el aumento sostenido de los niveles circulantes de estrógenos estimula el centro cíclico del hipotálamo (retroalimentación positiva) produciéndose el pico preovulatorio de LH. Este pico desencadena la maduración final del folículo, la ovulación y la luteinización de la estructura folicular remanente, con la consecuente formación del cuerpo lúteo (Hafez, 1987).

Por otro lado, los folículos en crecimiento secretan inhibina, la cual actúa sobre la hipófisis inhibiendo hasta niveles muy bajos la secreción de FSH sin alterar la secreción de LH. Estos niveles hormonales producen la atresia de los folículos subordinados de la onda folicular (Bo Caccia, 2003). La razón por la cual el folículo dominante puede crecer con niveles reducidos de FSH mientras que los subordinados se atresian, se relacionaría con la síntesis del receptor de LH (LHR) en las células de la granulosa del folículo dominante (Ginther et al., 1996). To- 